\title{
Laboratory monitoring of rivaroxaban in Chinese patients with deep venous thrombosis: a preliminary study
}

\author{
Ying $\mathrm{Li}^{1,2}$, Liping $\mathrm{Du}^{1}$, Xiaowan Tang ${ }^{1}$, Yuexin Chen $^{3^{*}}$ and Dan Mei ${ }^{*^{*}}$ (D)
}

\begin{abstract}
Background: Rivaroxaban, a novel oral anticoagulant drug, is widely used in clinical practice. There is no standardized laboratory monitoring for rivaroxaban, and its plasma concentration in Chinese patients with deep vein thrombosis is unclear. The rivaroxaban concentrations in human plasma and determine the steady-state concentration of rivaroxaban in patients with deep vein thrombosis are needed.
\end{abstract}

Methods: An ultra-high-performance liquid chromatography with mass spectrometric detection method was developed. Chromatographic separation was performed on a Waters BEH C18 column with isocratic elution using a mobile phase composed of acetonitrile and water. Quantitation of the analytes was performed using positive ionization mode and mass transitions of $\mathrm{m} / \mathrm{z} 437.3 \rightarrow \mathrm{m} / \mathrm{z} 145.0$ and $\mathrm{m} / \mathrm{z} 440.1 \rightarrow \mathrm{m} / \mathrm{z} 145.0$ for rivaroxaban and the internal standard, respectively. Blood samples were collected at $0 \mathrm{~h}$ and $2 \mathrm{~h}$ after patients took rivaroxaban for 7 days or more.

Results: The method was validated over the concentration range of $0.5 \sim 400 \mathrm{ng} \cdot \mathrm{mL}^{-1}$ with a very low limit of quantification of $0.5 \mathrm{ng} \cdot \mathrm{mL}^{-1}$, and the intra- and inter-day precision (RSD\%) were $<15 \%$. The range of the steady state concentration in patients that took $15 \mathrm{mg}$ rivaroxaban twice daily, $10 \mathrm{mg}$ twice daily, $20 \mathrm{mg}$ once daily, $15 \mathrm{mg}$ once daily, and $10 \mathrm{mg}$ once daily were $168.5 \sim 280.1 \mathrm{ng} \cdot \mathrm{mL}^{-1}, 74.2 \sim 271.4 \mathrm{ng} \cdot \mathrm{mL}^{-1}, 25.7 \sim 306.8 \mathrm{ng} \cdot \mathrm{mL}^{-1}, 24.5 \sim$ $306.4 \mathrm{ng} \cdot \mathrm{mL}^{-1}$, and $15.4 \sim 229.2 \mathrm{ng} \cdot \mathrm{mL}^{-1}$, respectively.

Conclusions: The plasma rivaroxaban concentration in patients who took $10 \mathrm{mg}$ rivaroxaban twice daily fluctuated less than that in patients who took $20 \mathrm{mg}$ rivaroxaban once daily. The plasma concentration can be used for therapeutic drug monitoring for rivaroxaban.

Keywords: Rivaroxaban, UPLC-MS/MS, DVT, Concentration monitoring

\footnotetext{
* Correspondence: cyuexin2007@163.com; meidanpumch@163.com

${ }^{3}$ Department of Vascular Surgery, Peking Union Medical College Hospital, Chinese Academy of Medical Sciences and Peking Union Medical College, Beijing 100730, China

'Department of Pharmacy, Peking Union Medical College Hospital, Chinese

Academy of Medical Sciences and Peking Union Medical College, Beijing 100730, China

Full list of author information is available at the end of the article
}

(c) The Author(s). 2020 Open Access This article is licensed under a Creative Commons Attribution 4.0 International License, which permits use, sharing, adaptation, distribution and reproduction in any medium or format, as long as you give appropriate credit to the original author(s) and the source, provide a link to the Creative Commons licence, and indicate if changes were made. The images or other third party material in this article are included in the article's Creative Commons licence, unless indicated otherwise in a credit line to the material. If material is not included in the article's Creative Commons licence and your intended use is not permitted by statutory regulation or exceeds the permitted use, you will need to obtain permission directly from the copyright holder. To view a copy of this licence, visit http://creativecommons.org/licenses/by/4.0/ The Creative Commons Public Domain Dedication waiver (http://creativecommons.org/publicdomain/zero/1.0/) applies to the data made available in this article, unless otherwise stated in a credit line to the data. 


\section{Background}

Rivaroxaban is an oral anticoagulant that directly inhibits activated factor X (FXa) and is effective in the prevention of venous thromboembolism after orthopaedic surgery. Studies have demonstrated that the anticoagulant effect of rivaroxaban is similar to that of vitamin $\mathrm{K}$ antagonist (VKA), and there is no difference in the first major or clinically relevant nonmajor bleeding risk between rivaroxaban and VKA [1, 2]. Rivaroxaban can also reduce the major bleeding risk and increase the risk of gastrointestinal bleeding compared to vitamin $\mathrm{K}$ antagonist (VKA) [1]. Moreover, rivaroxaban has been reported to have predictable pharmacokinetics and pharmacodynamics $[3,4]$. While routine monitoring is not required, there are many situations in which the need to assess the anticoagulant effect is required for clinicians to make treatment decisions, including acute renal failure, prior to an urgent surgery, during lifethreatening bleeding, a stroke, suspected accumulation of a drug, and when determining potential drug-drug interactions [5]. Coagulation monitoring can aid in clinical decisions, and clinical pharmacists can make anticoagulant recommendations to doctors according to monitoring results.

We can monitor the international normalized ratio (INR) to assess the effect and safety of warfarin. However, there are no specific monitoring indicators for rivaroxaban. Prothrombin time (PT) clotting times are significantly influenced by the thromboplastin used in varying PT reagents. The activated partial thromboplastin time (aPTT) has poor sensitivity and specificity and lacks an optimal dose-response relationship for monitoring rivaroxaban. Several studies [6-8] have shown that there is a linear relationship between anti-factor Xa activity and the concentration of rivaroxaban, and Kozue et al [9] indicated that measurement of anti-factor Xa activity might be useful for assessing the pharmacodynamics of high-risk patients. However, anti-factor Xa activity is not widely used in clinical monitoring. In addition, there are differences in coagulation function between Chinese and Caucasian populations. There are longer aPTT as well as lower protein $\mathrm{C}$ and $\mathrm{S}$ levels in Chinese individuals than in Caucasian individuals [10]. Individuals of East Asian origin (Chinese and Japanese) has been reported to have a significantly lower risk of venous thromboembolism $[11,12]$. However, there are no available studies on rivaroxaban monitoring in Chinese patients. Moreover, there is no specific, approved treatment in China for if a patient bleeds after taking rivaroxaban.

\section{Aim of the study}

The aim of our study was to determine rivaroxaban concentrations in real-world Chinese patients with deep vein thrombosis (DVT) by an ultra-performance liquid chromatography-tandem mass spectrometry (UPLC-MS/ MS) method to initially explore the correlation of the plasma concentration range and $\mathrm{PT}$, aPTT, and antifactor Xa activities and to determine a method for clinical monitoring of rivaroxaban.

\section{Ethics approval}

The study protocol was approved by the Ethics Committee of Peking Union Medical College Hospital (ZS1359). All subjects signed informed consent forms before the trial.

\section{Methods}

\section{Chemicals and reagents}

Rivaroxaban was provided by Bayer HealthCare AG (Wuppertal, Germany) (Fig. 1a). Rivaroxaban-d4, used as an internal standard (IS), was purchased from Toronto Research Chemicals (Canada) (Fig. 1b). Methanol and acetonitrile of HPLC grade were purchased from Thermo Fisher (MA, USA). LCMS-grade formic acid and dimethyl sulfoxide (DMSO) of analytical grade were purchased from JK Chemical (Beijing, China) and Sigma-Aldrich (France), respectively. Water was purified with a Milli-Q system (Millipore Waters, Darmstadt, Germany).

\section{Calibrator and quality control sample preparation}

The powdered compound of rivaroxaban and rivaroxaban-d4 were dissolved in DMSO to prepare stock solutions at $100 \mu \mathrm{g} / \mathrm{mL}$ and then the stock solutions stored at $-20^{\circ} \mathrm{C}$. Further dilutions were made in methanol to obtain series of intermediate and final working solutions. Then the appropriate amount of working solutions were added in blank human plasma to get the calibration curve with concentrations $0.5,1,2,10,20,100$, 200 , and $400 \mathrm{ng} / \mathrm{mL}$ and quality control (QC) samples with concentrations $1.5,15$, and $300 \mathrm{ng} / \mathrm{mL}$.

\section{Instrument and analytical conditions}

An Acquity UPLC system (WATERS, Milford, MA, USA) with an autosampler temperature of $10^{\circ} \mathrm{C}$ and Acquity UPLC BEH C18 column $(2.1 \mathrm{~mm} \times 50 \mathrm{~mm}$, $1.7 \mu \mathrm{m}$ particle size; Waters, Milford, MA, USA) was applied to determine the samples in this study. The mobile phase consisted of acetonitrile (A) and ultrapure water (B), and the gradient programme of the mobile phase was as follows: $32 \% \mathrm{~A}$ at $0-1.5 \mathrm{~min} ; 32-90 \% \mathrm{~A}$ at $1.5-$ $1.51 \mathrm{~min} ; 90-32 \% \mathrm{~A}$ at $2.5-2.51 \mathrm{~min}$; and $32 \% \mathrm{~A}$ at 2.51-3 min. The flow rate and the column temperature were set at $0.4 \mathrm{~mL} / \mathrm{min}$ and $35^{\circ} \mathrm{C}$, respectively.

The analytes were detected in the Acquity tandem quadrupole detector (Waters Xevo TQ-S, Milford, MA, USA) with positive electrospray ionization $\left(\mathrm{ESI}^{+}\right)$and 

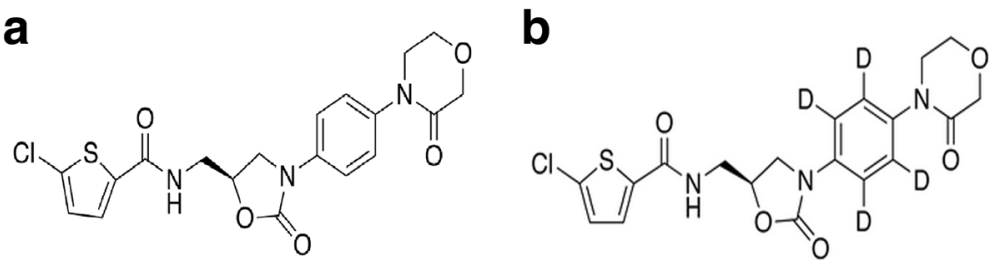

Fig. 1 a Rivaroxaban chemical structure; b Rivaroxaban-d4 chemical structure

multiple-reaction monitoring (MRM) mode. And the mass transitions were $\mathrm{m} / \mathrm{z} \quad 437 \rightarrow 145.0$ and $\mathrm{m} / \mathrm{z}$ $440.1 \rightarrow 145.0$ for rivaroxaban and rivaroxaban-d4, respectively. The operating parameters were as follows: cone voltage, $35 \mathrm{~V}$; collision voltage, $30 \mathrm{~V}$; collision gas flow, $0.16 \mathrm{~mL} / \mathrm{min}$; nebulizer gas pressure, $7.0 \mathrm{bar}$; and desolvation temperature, $500{ }^{\circ} \mathrm{C}$. The retention times were $1.03 \mathrm{~min}$ for both rivaroxaban and rivaroxaban-d4.

\section{Sample pretreatment}

Sample preparation was performed by protein precipitation with acetonitrile. A $50 \mu \mathrm{L}$ aliquot of plasma sample and $150 \mu \mathrm{L}$ of acetonitrile containing the IS at a concentration of $10 \mathrm{ng} / \mathrm{mL}$ were mixed and vortexed for $2 \mathrm{~min}$, then the mixture was centrifuged at $13000 \mathrm{r} / \mathrm{min}$ for 10 min at $25^{\circ} \mathrm{C}$. The supernatant was dried under nitrogen at normal temperature, redissolved with $32 \%$ acetonitrile and $68 \%$ ultrapure water containing $0.2 \%$ formic acid and vortexed. After filtering through a $0.22 \mu \mathrm{m}$ micromembrane filter, the supernatant was transferred to an autosampler vial and $10 \mu \mathrm{L}$ was injected into the UPLC system automatically.

\section{Study design and patients}

The study population consisted of adult subjects with deep venous thrombosis (DVT) from Peking Union Medical College Hospital. Eligible subjects were those treated with rivaroxaban and aged 18 or older. Subjects were ineligible if they had severe damage to liver and kidney function, severe cardiopulmonary insufficiency, or they combined other anticoagulants, such as CYP450 3A4 and strong P-glycoprotein inhibitors.

The clinician conducted drug administration based on the patients' condition. There were some patients who did not have very severe clots or bleeding after taking $20 \mathrm{mg}$ rivaroxaban. Clinicians typically consider giving these patients $10 \mathrm{mg}$ bid or $15 \mathrm{mg}$ qd rivaroxaban. Rivaroxaban (Bayer HealthCare AG, Wuppertal, Germany) was taken with food. When concentrations of rivaroxaban reached a steady state (day seven or later), blood samples were taken $2 \mathrm{~h}$ after administration and before the next dose. To ensure patient adherence, we sent text messages to patients to remind them to take the medication and asked patients to fill out medication record forms. Patients continued to take rivaroxaban for at least 3 months. All samples were centrifuged for $10 \mathrm{~min}$ at $3000 \times \mathrm{g}$, and the plasma was then stored at $-80^{\circ} \mathrm{C}$ until analysis.

\section{Sample analysis}

Rivaroxaban plasma concentrations were determined by UPLC-MS/MS. PT, aPTT and anti-factor Xa activity were determined at the same time in the clinical laboratory of Peking Union Medical College Hospital.

Statistical analyses were performed using SPSS software (SPSS for Windows, version 20.0, IBM Corp, Armonk, NY, USA). The arithmetic mean was calculated, and the results are presented as the mean \pm standard deviation (SD). The association between PT, aPTT, anti-factor Xa activity and rivaroxaban plasma concentrations by UPLC-MS/MS was determined by Spearman correlation.

\section{Results \\ Method validation \\ Selectivity}

Six lots different blank plasma were determined to analyze selectivity. The retention time $\left(t_{R}\right)$ was 1.03 min for rivaroxaban and IS. The analysis showed no endogenous peaks at the same time, since the responses of endogenous peaks were lower $20 \%$ of lower limit of quantification (LLOQ) (Fig. 2).

\section{Accuracy and precision}

Six samples for each concentration of QC samples (1.5, 15 and $300 \mathrm{ng} / \mathrm{mL}$ ) were processed and analysed to obtain intra-run precision and accuracy. Then three different sequences were measured successively to obtain inter-run precision and accuracy. The ratio between the measured concentration and the nominal concentration multiplied by $100 \%$ was used as the accuracy. The relative standard deviation indicates precision. Intra- and inter-day imprecision and accuracy outcomes of QC samples are shown in Table 1 and were all below $\pm 15 \%$. This method was then determined to be accurate and precise. 

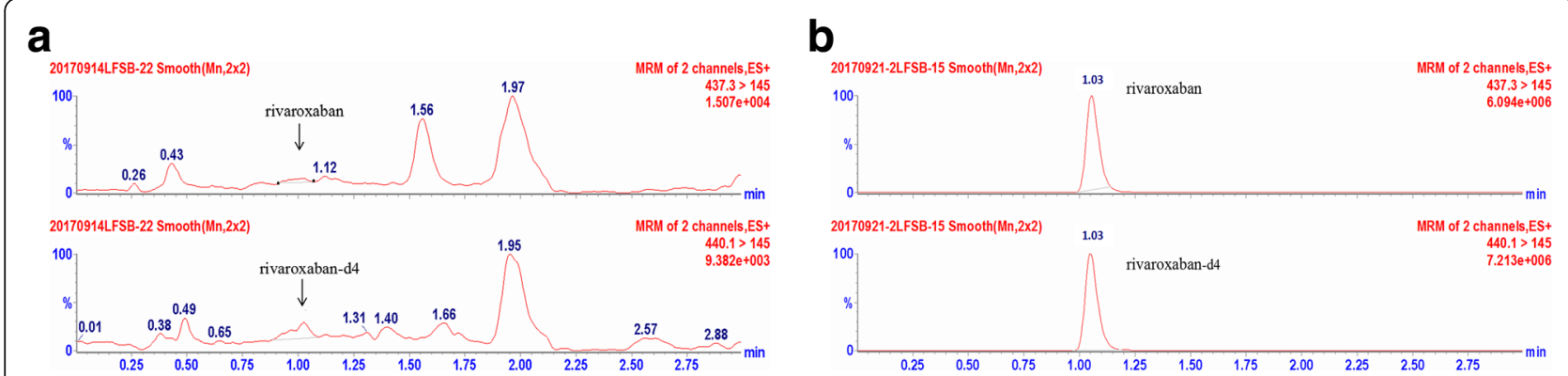

Fig. 2 The MRM mass chromatograms of rivaroxaban and d4-rivaroxaban: a blank plasma; b human plasma with $0.5 \mathrm{ng} / \mathrm{mL}$ rivaroxaban and 10 $\mathrm{ng} / \mathrm{mL}$ internal standard

\section{Linearity}

A calibration curve was established by plotting the peak area ratios of rivaroxaban to the IS (Y-axis) versus the nominal concentration of rivaroxaban (X-axis) through weighted least-squares linear regression analysis with a weighting factor of $1 / \mathrm{x}^{2}$. The linear regression equation was the mean of three batches discussed in the section titled "Accuracy and precision", and the equation was $y=0.0047 x-0.0119$ for rivaroxaban with a correlation coefficient $r^{2}=0.996$. The linear range was 0.5 to $400 \mathrm{ng} /$ $\mathrm{mL}$, and the accuracy of the LLOQ $(0.5 \mathrm{ng} / \mathrm{mL})$ was 80 $\sim 120 \%$ with the precision $\leq 20 \%$.

\section{Matrix effect and extraction recovery}

The matrix effect was assessed six times by comparing the concentrations obtained with three solutions at 1.5, 15 and $300 \mathrm{ng} / \mathrm{mL}$ in blank plasma extracts with those of standard rivaroxaban solutions at the same concentrations. The extraction recovery was determined six times by comparing three levels of samples (1.5, 15 and 300 $\mathrm{ng} / \mathrm{mL}$ ) with reference solutions containing blank plasma extracts spiked with rivaroxaban at the same concentrations. The results are shown in Table 1 and remained stable over the linear range.

\section{Stability}

Three concentrations $(1.5,15$ and $300 \mathrm{ng} / \mathrm{mL})$ of rivaroxaban in plasma samples were assessed six times respectively, and then these plasma samples were stored at room temperature $\left(25^{\circ} \mathrm{C}\right)$ up to $24 \mathrm{~h}$, at $-30{ }^{\circ} \mathrm{C}$ up to 3 months, in an autosampler at $10^{\circ} \mathrm{C}$ up to $48 \mathrm{~h}$ and repeatedly frozen and thawed 3 times. Stability was defined as the ratio of each concentration to the concentration of the first day. The results are presented as the mean \pm SD (Table 2). Rivaroxaban was stable under all tested conditions since the difference of average measured concentrations and theoretical concentrations was within $\pm 15 \%$.

\section{Patient concentrations \\ Subjects}

Of the 44 patients enrolled in the early study, 5 were eliminated because of no follow-up; 73 plasma samples from 39 subjects were included in these analyses. Based on the condition, these patients took rivaroxaban $15 \mathrm{mg}$ twice daily (BID, $n=3$ ), $10 \mathrm{mg}$ twice daily (BID, $n=9$ ), $20 \mathrm{mg}$ once daily (QD, $n=8$ ), $15 \mathrm{mg}$ once daily (QD, $n=$ 7 ), or $10 \mathrm{mg}$ once daily (QD, $n=12$ ). The groups were well matched with respect to demographic characteristics (Table 3). The mean age of the subjects was 56.9 years. Minor between-group differences in $\mathrm{BMI}, \mathrm{CrCl}$, ALT and Alb were not statistically significant.

\section{Plasma concentrations}

The steady-state trough concentrations in patients with DVT that took $15 \mathrm{mg}$ rivaroxaban BID, $10 \mathrm{mg}$ BID, $20 \mathrm{mg}$ QD, $15 \mathrm{mg}$ QD, and $10 \mathrm{mg}$ QD were $168.5 \mathrm{ng} \bullet \mathrm{mL}^{-1}(95 \%$ CI, 162.5 to $\left.499.5 \mathrm{ng} \cdot \mathrm{mL}^{-1}\right), 74.2 \mathrm{ng} \cdot \mathrm{mL}^{-1}(95 \% \mathrm{CI}, 44.7$ to $\left.103.6 \mathrm{ng} \cdot \mathrm{mL}^{-1}\right), 25.7 \mathrm{ng} \cdot \mathrm{mL}^{-1}(95 \% \mathrm{CI}, 10.0$ to 42.3 $\left.\mathrm{ng} \cdot \mathrm{mL}^{-1}\right), 24.5 \mathrm{ng} \cdot \mathrm{mL}^{-1}\left(95 \% \mathrm{CI}, 11.4\right.$ to $\left.37.4 \mathrm{ng} \cdot \mathrm{mL}^{-1}\right)$ and $15.4 \mathrm{ng} \cdot \mathrm{mL}^{-1}\left(95 \% \mathrm{CI}, 7.6\right.$ to $\left.23.2 \mathrm{ng} \cdot \mathrm{mL}^{-1}\right)$, respectively. The steady-state peak concentrations were 280.1

Table 1 Accuracy, precision, matrix effect and extraction recovery of rivaroxaban concentrations in human plasma

\begin{tabular}{|c|c|c|c|c|c|c|c|c|}
\hline \multirow{2}{*}{$\begin{array}{l}\text { Theoretical concentration } \\
(\mathrm{ng} / \mathrm{mL})\end{array}$} & \multicolumn{2}{|c|}{ Intra-run accuracy and precision } & \multicolumn{2}{|c|}{ Inter-run accuracy and precision } & \multicolumn{2}{|c|}{ Matrix effect (\%) } & \multicolumn{2}{|c|}{ Extraction recovery (\%) } \\
\hline & Accuracy (\%) & Precision- RSD (\%) & Accuracy (\%) & Precision- RSD (\%) & mean $\pm S D$ & RSD & mean $\pm S D$ & RSD \\
\hline 0.5 (LLOQ) & 103.57 & 14.05 & 96.68 & 14.95 & - & - & - & - \\
\hline 1.5 & 88.02 & 1.80 & 88.55 & 2.47 & $109.78 \pm 2.33$ & 2.12 & $75.18 \pm 2.14$ & 2.84 \\
\hline 15.0 & 94.45 & 0.69 & 93.34 & 4.21 & $113.81 \pm 0.67$ & 0.59 & $79.62 \pm 2.54$ & 3.20 \\
\hline 300.0 & 99.12 & 4.60 & 99.90 & 4.13 & $106.44 \pm 0.92$ & 0.86 & $87.53 \pm 3.31$ & 3.78 \\
\hline
\end{tabular}

RSD Relative standard deviation, SD Standard deviation 
Table 2 Rivaroxaban stability in spiked samples

\begin{tabular}{lllll}
\hline $\begin{array}{l}\text { Theoretical concentrations } \\
(\mathrm{ng} / \mathrm{mL})\end{array}$ & $\begin{array}{l}\text { Room temperature } \\
\left(25^{\circ} \mathrm{C}\right) \text { up to } 24 \mathrm{~h}\end{array}$ & $-30^{\circ} \mathrm{C}$ up to 3 months & $\begin{array}{l}\text { In autosampler at } \\
10^{\circ} \mathrm{C} \text { up to } 48 \mathrm{~h}\end{array}$ & $\begin{array}{l}\text { Frozen and thawed } \\
3 \text { times }\end{array}$ \\
\hline 1.5 & $92.23 \pm 4.84$ & $89.67 \pm 1.47$ & $90.65 \pm 2.00$ & $95.08 \pm 1.04$ \\
15.0 & $85.45 \pm 1.05$ & $96.08 \pm 1.38$ & $97.78 \pm 2.27$ & $104.35 \pm 1.03$ \\
300.0 & $95.45 \pm 1.26$ & $102.68 \pm 2.89$ & $107.23 \pm 2.03$ & $110.92 \pm 1.62$ \\
\hline
\end{tabular}

$\mathrm{ng} \cdot \mathrm{mL}^{-1}\left(95 \% \mathrm{CI}, 99.3\right.$ to $\left.659.4 \mathrm{ng} \cdot \mathrm{mL}^{-1}\right), 271.4 \mathrm{ng} \cdot \mathrm{mL}^{-1}$ (95\% CI, 109.0 to $\left.361.7 \mathrm{ng} \cdot \mathrm{mL}^{-1}\right), 306.8 \mathrm{ng} \cdot \mathrm{mL}^{-1}(95 \%$ $\mathrm{CI}, 240.3$ to $\left.376.6 \mathrm{ng} \cdot \mathrm{mL}^{-1}\right), 306.4 \mathrm{ng} \cdot \mathrm{mL}^{-1}(95 \% \mathrm{CI}$, 222.4 to $\left.390.3 \mathrm{ng} \cdot \mathrm{mL}^{-1}\right)$ and $229.2 \mathrm{ng} \cdot \mathrm{mL}^{-1}(95 \% \mathrm{CI}$, 170.0 to $288.4 \mathrm{ng} \cdot \mathrm{mL}^{-1}$ ) for the abovementioned dosages, respectively. There was a statistically significant difference $(p=0.008)$ in the trough concentration between the two dosage groups of $10 \mathrm{mg}$ BID and $20 \mathrm{mg}$ QD, but there was no statistically significant difference $(p=0.521)$ in the peak concentration. The plasma concentration in patients who took $10 \mathrm{mg}$ rivaroxaban BID was more stable than that in patients who took $20 \mathrm{mg}$ rivaroxaban QD.

\section{Pharmacokinetic and pharmacodynamic correlation}

Anti-factor Xa activity, PT and aPTT were correlated with the plasma concentration of rivaroxaban $(r=0.985$, $r=0.827$ and $r=0.807$, respectively) (Fig. 3). There was a linear relationship between concentration and antifactor Xa activity.

\section{Discussion}

On account of predictable anticoagulant effects and relatively low bleeding risk or few drug interactions, new oral anticoagulants have become more widely available for clinical use. The European Heart Rhythm Association (EHRA) guidelines [13] recommend clinical assessment and noncoagulation monitoring every $1 \sim 6$ months for patients taking DOACs but do not recommend any monitoring of coagulation assays. However, clinical practices have shown that clinicians need laboratory monitoring to help them make clinical decisions.

In this study, a UPLC-MS/MS method was developed and validated for rivaroxaban quantification using simple sample preparation and chromatographic conditions. In our study of real-world patients under rivaroxaban treatment, we reached an LLOQ of $0.5 \mathrm{ng} \bullet \mathrm{mL}^{-1}$. Previous studies have shown that rivaroxaban samples were stable at $20^{\circ} \mathrm{C},+4{ }^{\circ} \mathrm{C}$ and $-20^{\circ} \mathrm{C}$ for up to $24 \mathrm{~h}, 48 \mathrm{~h}, 5$ days, and 1 and 3 months $[14,15]$. We first studied the stability of rivaroxaban samples stored at $25^{\circ} \mathrm{C}$ for $24 \mathrm{~h}$, $30{ }^{\circ} \mathrm{C}$ for 3 months and in an autosampler at $10^{\circ} \mathrm{C}$ for up to $48 \mathrm{~h}$ to ensure the stability of rivaroxaban throughout the experiment. Our method was shown to be rapid, specific, reliable and suitable for the determination of rivaroxaban in plasma. This article evaluated the extraction recovery rather than the method recovery, exhibiting an average extraction recovery of approximately $80 \%$. It is possible that the tube used in drying the supernatant under nitrogen had adsorbed some of the rivaroxaban, but the RSD of the three levels of extraction recoveries was $7.74 \%$. Thus, the recovery of this method remained stable over the linear range. We evaluated the relevance of different coagulation assays for determining the rivaroxaban concentration and effect by comparing them with the results of the LC-MS/MS method. PT and $\mathrm{aPTT}$ were correlated with the plasma concentration of rivaroxaban in the study, but the relationships were not linear, so they cannot be used for assessing the concentration of rivaroxaban. Douxfils et al [16] indicated that PT may provide some quantitative information, even though the sensitivity of the different PT reagents varies importantly. In contrast, the relationship of anti-factor Xa activity and concentration was linear, so anti-factor Xa activity can be used to estimate concentrations of rivaroxaban. The limitation was that the LLOQ of anti-factor Xa activity was $25 \mathrm{ng} \bullet \mathrm{mL}^{-1}$. At very low concentrations, i.e., $\leq 25 \mathrm{ng} \cdot \mathrm{mL}^{-1}$, the method is less reliable, and an LC-MS/MS method is still required [14].

The dosage regimens of rivaroxaban are $15 \mathrm{mg}$ BID, $20 \mathrm{mg}$ QD or $10 \mathrm{mg}$ QD in the drug instructions of China. Clinicians often make clinical administration

Table 3 Demographic characteristics of subjects enrolled in the study

\begin{tabular}{|c|c|c|c|c|c|c|c|c|}
\hline & & $\begin{array}{l}15 \mathrm{mg} \text { BID } \\
(n=3)\end{array}$ & $\begin{array}{l}10 \mathrm{mg} \text { BID } \\
(n=9)\end{array}$ & $\begin{array}{l}20 \mathrm{mg} \text { QD } \\
(n=8)\end{array}$ & $\begin{array}{l}15 \mathrm{mg} Q \mathrm{QD} \\
(n=7)\end{array}$ & $10 \mathrm{mg}$ QD $(n=12)$ & Total $(n=39)$ & $P$ \\
\hline \multirow[t]{5}{*}{ Demographic characteristics } & Age & $50.0 \pm 3.0$ & $56.4 \pm 13.3$ & $49.1 \pm 17.6$ & $60.9 \pm 10.5$ & $63.4 \pm 14.6$ & $56.9 \pm 14.8$ & 0.147 \\
\hline & $\mathrm{BMI}\left(\mathrm{kg} / \mathrm{m}^{2}\right)$ & $26.1 \pm 2.3$ & $23.7 \pm 2.5$ & $23.2 \pm 3.8$ & $26.6 \pm 4.4$ & $22.9 \pm 2.4$ & $23.9 \pm 3.3$ & 0.126 \\
\hline & $\mathrm{CrCl}\left(\mathrm{mL} \cdot \mathrm{min}^{-1}\right)$ & $110.4 \pm 31.5$ & $100.6 \pm 27.5$ & $91.9 \pm 35.1$ & $84.4 \pm 20.1$ & $76.6 \pm 34.2$ & $89.6 \pm 31.5$ & 0.334 \\
\hline & $\operatorname{ALT}\left(U \cdot L^{-1}\right)$ & $18.7 \pm 3.5$ & $17.0 \pm 8.2$ & $30.4 \pm 12.8$ & $23.8 \pm 16.4$ & $18.7 \pm 12.1$ & $22.1 \pm 12.5$ & 0.092 \\
\hline & Alb $\left(g \cdot L^{-1}\right)$ & $43.7 \pm 6.7$ & $39.9 \pm 5.1$ & $42.2 \pm 6.4$ & $39.7 \pm 5.9$ & $41.8 \pm 4.0$ & $41.3 \pm 5.2$ & 0.694 \\
\hline
\end{tabular}



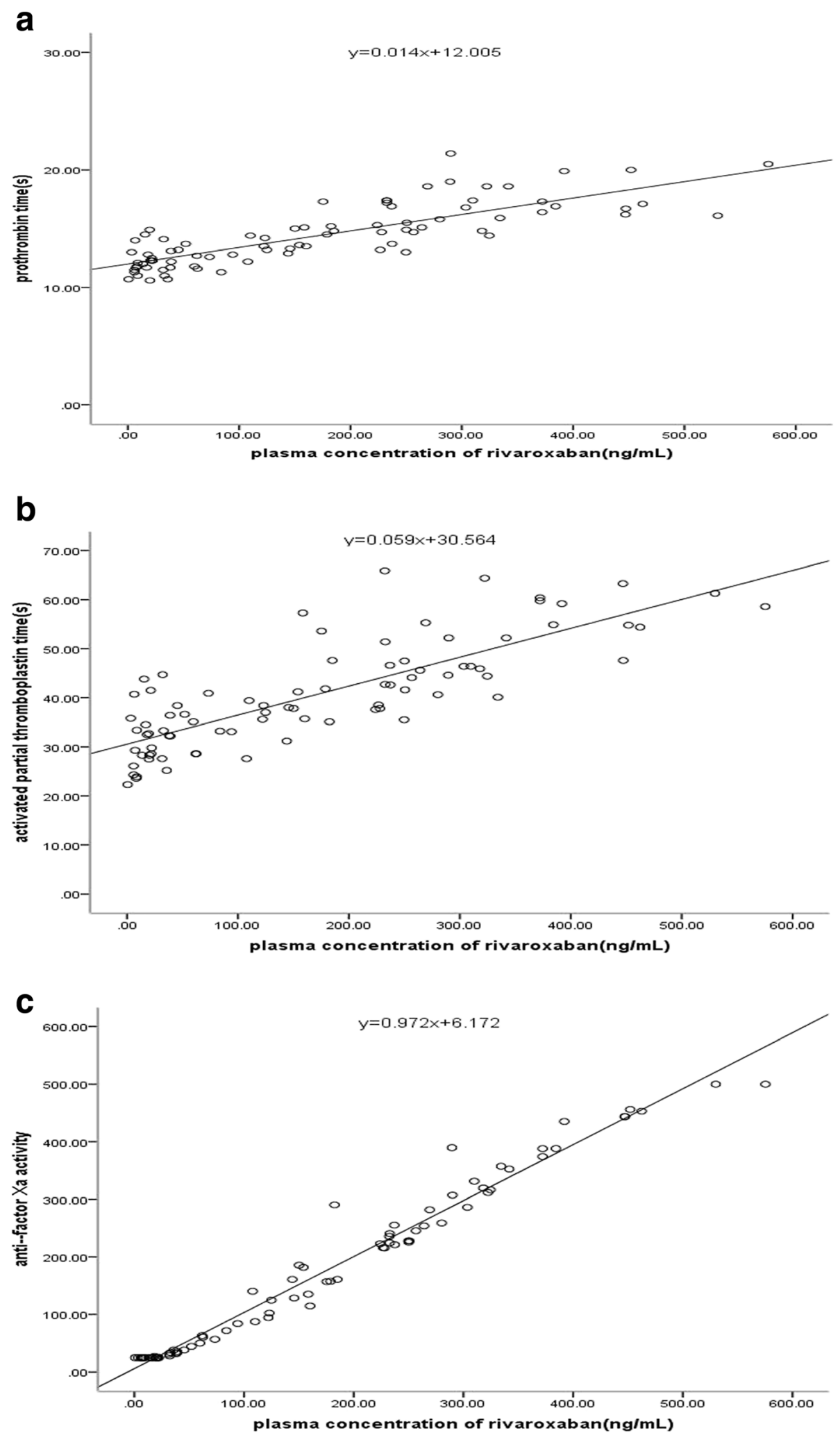

Fig. 3 Correlation between plasma concentration of rivaroxaban and PT (a), aPTT (b) or anti-factor Xa activity (c) 
Table 4 Published studies on the pharmacokinetics of rivaroxaban in patients (mean)

\begin{tabular}{|c|c|c|c|c|c|c|c|}
\hline Patients & Demographic information & Age & Dosage & $C_{\max }\left(n g \cdot \mathrm{mL}^{-1}\right)$ & $C_{\text {trough }}\left(\mathrm{ng} \cdot \mathrm{mL}^{-1}\right)$ & $C L / F\left(L \cdot h^{-1}\right)$ & $\mathrm{Vd}(\mathrm{L})$ \\
\hline Undergoing total hip replacement [17] & Caucasian & $27 \sim 93$ & $10 \mathrm{mg} \mathrm{qd}$ & $124.6^{a}$ & $9.1^{a}$ & 7.3 & 49.1 \\
\hline Deep venous thrombosis [18] & Caucasian & $18 \sim 91$ & $20 \mathrm{mg}$ qd & 270 & 25.5 & 5.67 & 54.4 \\
\hline Non-valvular atrial fibrillation [19] & Caucasian & $51 \sim 92$ & $20 \mathrm{mg} \mathrm{qd}$ & 290 & 32 & 6.1 & 79.7 \\
\hline
\end{tabular}

amedian; -, not published

schemes based on the patients' condition. The realworld patients in the study took either $15 \mathrm{mg}$ rivaroxaban BID, $10 \mathrm{mg}$ BID, $20 \mathrm{mg}$ QD, $15 \mathrm{mg}$ QD or $10 \mathrm{mg}$ QD. Compared with studies of Caucasian patients [1719], the peak concentration of rivaroxaban was higher in this study (Table 4). The peak concentrations of $10 \mathrm{mg}$ QD and $20 \mathrm{mg}$ QD were $229.2 \mathrm{ng} \bullet \mathrm{mL}^{-1}$ and 306.8 $\mathrm{ng} \cdot \mathrm{mL}^{-1}$, respectively, in this study, while they were $124.6 \mathrm{ng} \cdot \mathrm{mL}^{-1}$ [17] and $270 \mathrm{ng} \cdot \mathrm{mL}^{-1}$ [18] or 290 $\mathrm{ng} \cdot \mathrm{mL}^{-1}$ [19], respectively, in Caucasians. The apparent distribution volume of rivaroxaban was approximately $50 \sim 80 \mathrm{~L}$ [18-21], which was beyond the total liquid volume, and some rivaroxaban was distributed in tissues or organs. The body mass index (BMI) in previous studies was $27.6-31.6 \mathrm{~kg} / \mathrm{m}^{2}[17,21]$, and the maximum BMI of Chinese patients in this study was $26.6 \mathrm{~kg} / \mathrm{m}^{2}$. However, Kubitza's study [22] claimed that body weight did not alter rivaroxaban pharmacokinetics. Many factors can affect the rivaroxaban concentration, such as adherence, renal function, co-medication and so on. The sample size of existing research is small; thus, more studies are needed to identify the reasons for the difference.

Fox et al. [23] stated that the once daily and twice daily dosing had similar therapeutic effects, and the former had a lower risk of bleeding; therefore, the dosage regimen of rivaroxaban was once daily. In this study, performed on real-life patients with DVT treated with rivaroxaban according to current clinical routines, the trough concentration of $10 \mathrm{mg}$ BID was higher than that of $20 \mathrm{mg}$ QD, and there was no significant difference in the peak concentration. In terms of pharmacokinetics, $10 \mathrm{mg}$ BID rivaroxaban had an advantage over $20 \mathrm{mg}$ QD rivaroxaban because the concentration fluctuated less. We obtained blood samples $2 \mathrm{~h}$ after administration and before the next dose. We could not guarantee that every patient did not miss their medication, but we took certain measures, such as sending text messages to patients to remind them to take the medication and asking patients to fill out medication record forms. In addition, the trough concentration was lower in Chinese patients in this study than in Caucasian patients [19], so a dosage of $10 \mathrm{mg}$ rivaroxaban BID may have better efficacy than $20 \mathrm{mg}$ QD. There were significant individual differences in the plasma rivaroxaban concentration, which increased the risk of clinical use of rivaroxaban. Coagulation monitoring is even more necessary for patients with acute renal failure, prior to urgent surgery, during lifethreatening bleeding, during a stroke, during overdose and in the suspected accumulation of a drug.

Considering that this was not a clinical trial for a new drug and that there have been similar studies before, we did not perform "incurred sample reanalysis". We analysed the results from 39 patients. This sample size was too small and was not enough to represent all Chinese patients with DVT. However, the above study was only the early results of a comprehensive study, and additional patients are still enrolled for further research.

\section{Conclusion}

The UPLC-MS/MS method met the requirements of FDA guidelines for biological analysis methods and was rapid, accurate, sensitive and repeatable to determine the concentration of rivaroxaban in Chinese plasma. The LLOQ of $0.5 \mathrm{ng} / \mathrm{mL}$ could cover the minimum clinical concentration and the calibration range was $0.5 \sim 400.0$ $\mathrm{ng} / \mathrm{mL}$. The error of inter- and intra-day accuracy and precision was less than $\pm 15 \%$ and the stability of this method met the requirements. This method was successfully applied to plasma samples of 39 Chinese patients, and the plasma concentration range of rivaroxaban was obtained. Moreover, there is a basis for further anticoagulation monitoring research, and anticoagulant clinical pharmacists may provide recommendations for the clinical application of rivaroxaban to promote medication safety in the future.

\section{Abbreviations \\ FXa: Factor Xa; VKA: Vitamin K antagonist; INR: International normalized ratio; PT: Prothrombin time; aPTT: Activated partial thromboplastin time; DVT: Deep vein thrombosis; UPLC-MS/MS: Ultra-performance liquid chromatography- tandem mass spectrometry; QC: Quality control; ESI: Electrospray ionization; MRM: Multiple-reaction monitoring; SD: Standard deviation; LLOQ: Lower limit of quantification; EHRA: European Heart Rhythm Association}

\section{Acknowledgements}

We would like to thank the Clinical Pharmacology Research Center of Peking Union Medical College Hospital for providing help with the instruments and the laboratory of Peking Union Medical College Hospital for detecting PT, aPTT, and anti-factor Xa activity. The rivaroxaban standard was kindly provided by Bayer HealthCare AG, Wuppertal, Germany.

\section{Authors' contributions}

YL contributed to all aspects, including the conception and design of the experiments, acquisition, analysis, and interpretation of data, and drafting of the manuscript. LPD contributed to drafting of the manuscript. XWT contributed to acquiring data. DM designed the experiments, interpreted the data and contributed to drafting of the manuscript. YXC contributed to 
revising the intellectual content and final approval of the version to be published. All authors have read and approve of the final version.

\section{Funding}

The materials were supported by the CAMS Innovation Fund for Medical Science (CAMS-2017-12M-1-011). The funding source had no role in the design of this study and did not have any role during the collection, analysis, and interpretation of the data, as well as in the preparation of the manuscript.

\section{Availability of data and materials}

The data used in the current study can be accessed by request via the corresponding author.

\section{Ethics approval and consent to participate}

The study protocol was approved by the Ethics Committee of Peking Union Medical College Hospital (ZS-1359). All subjects signed informed consent before the trial.

\section{Consent for publication}

Not applicable.

\section{Competing interests}

The authors declare that they have no competing interests.

\section{Author details}

'Department of Pharmacy, Peking Union Medical College Hospital, Chinese Academy of Medical Sciences and Peking Union Medical College, Beijing 100730, China. ${ }^{2}$ Department of Pharmacy, National Cancer Center/Cancer Hospital, Chinese Academy of Medical Sciences and Peking Union Medical College, Beijing 100021, China. ${ }^{3}$ Department of Vascular Surgery, Peking Union Medical College Hospital, Chinese Academy of Medical Sciences and Peking Union Medical College, Beijing 100730, China.

Received: 15 September 2019 Accepted: 12 May 2020

Published online: 28 May 2020

\section{References}

1. Bauersachs R, Berkowitz SD, Brenner B, Buller HR, Decousus H, Gallus AS, Lensing AW, Misselwitz F. Oral rivaroxaban for symptomatic venous thromboembolism. New Engl J Med. 2010;363:2499-510.

2. Prins $\mathrm{MH}$, Lensing $\mathrm{AW}$, Bauersachs $\mathrm{R}$, van Bellen $\mathrm{B}$, Bounameaux $\mathrm{H}$. Oral rivaroxaban versus standard therapy for the treatment of symptomatic venous thromboembolism: a pooled analysis of the EINSTEIN-DVT and PE randomized studies. Thromb J. 2013;11(1):21-31.

3. Mueck W, Stampfuss J, Kubitza D, Becka M. Clinical pharmacokinetic and pharmacodynamic profile of rivaroxaban. Clin Pharmacokinet. 2014;53(1):116

4. Kreutz R. Population pharmacokinetics and pharmacodynamics of rivaroxaban - an oral, direct factor Xa inhibitor. Curr Clin Pharmacol. 2014; 9(1):75-83.

5. Conway SE, Hwang AY, Ponte CD, Gums JG. Laboratory and clinical monitoring of direct acting oral anticoagulants: what clinicians need to know. Pharmacotherapy. 2017;37(2):236-48.

6. Beyer J, Trujillo T, Fisher S, Ko A, Lind SE, Kiser TH. Evaluation of a heparincalibrated antifactor Xa assay for measuring the anticoagulant effect of oral direct Xa inhibitors. Clin Appl Thromb Hemost. 2016;22(5):423-8.

7. Bardy G, Fischer F, Appert A, Baldin B, St Ve M, Spreux A, Lavrut T, Drici M. Is anti-factor Xa chromogenic assay for rivaroxaban appropriate in clinical practice? Advantages and comparative drawbacks. Thromb Res. 2015;136(2): 396-401.

8. Zhang Y, Qian Q, Qian G. Laboratory monitoring of rivaroxaban and assessment of its bleeding risk. Br J Biomed Sci. 2017:73(3):134-9.

9. Ikeda K, Tachibana H. Clinical implication of monitoring rivaroxaban and apixaban by using anti-factor Xa assay in patients with non-valvular atrial fibrillation. J Arrhythm. 2016:32(1):42-50

10. Ho P, Ng C, Rigano J, Tacey M, Smith C, Donnan G, Nandurkar H. Significant age, race and gender differences in global coagulation assays parameters in the normal population. Thromb Res. 2017;154:80-3.

11. Roberts LN, Patel RK, Arya R. Venous thromboembolism and ethnicity. Brit 」 Hamatol. 2009;146(4):369-83.
12. Singhal D, Smorodinsky E, Guo L. Differences in coagulation among Asians and Caucasians and the implication for reconstructive microsurgery. J Reconstr Microsurg. 2011;27(01):57-62.

13. Heidbuchel $H$, Verhamme $P$, Alings $M$, Antz $M$, Diener $H$, Hacke $W$, Oldgren J, Sinnaeve P, Camm AJ, Kirchhof P. Updated European Heart Rhythm Association Practical Guide on the use of non-vitamin K antagonist anticoagulants in patients with non-valvular atrial fibrillation. Europace. 2015;17(10):1467-507.

14. Korostelev M, Bihan K, Ferreol L, Tissot N, Hulot J, Funck-Brentano C, Zahr NL. Simultaneous determination of rivaroxaban and dabigatran levels in human plasma by high-performance liquid chromatography-tandem mass spectrometry. J Pharmaceut Biomed. 2014;100:230-5.

15. Baldelli S, Cattaneo D, Pignatelli P, Perrone V, Pastori D, Radice S, Violi F, Clementi E. Validation of an LC-MS/MS method for the simultaneous quantification of dabigatran, rivaroxaban and apixaban in human plasma. Bioanalysis. 2016;8(4):275-83.

16. Douxfils J, Mullier F, Loosen C, Chatelain C, Chatelain B, Dogné J. Assessment of the impact of rivaroxaban on coagulation assays: laboratory recommendations for the monitoring of rivaroxaban and review of the literature. Thromb Res. 2012:130(6):956-66.

17. Mueck W, Borris LC, Dahl OE, Haas S, Huisman MV, Kakkar AK, Kalebo P, Muelhofer E, Misselwitz F, Eriksson BI. Population pharmacokinetics and pharmacodynamics of once- and twice-daily rivaroxaban for the prevention of venous thromboembolism in patients undergoing total hip replacement. Thromb Haemost. 2008;100(3):453-61.

18. Mueck W, Lensing AA, Agnelli G, Decousus H, Prandoni P, Misselwitz F. Population pharmacokinetic analyses in patients treated for acute deep-vein thrombosis and exposure simulations in patients with atrial fibrillation treated for stroke prevention. Clin Pharmacokinet. 2011;50(10):675-86.

19. Girgis IG, Patel MR, Peters GR, Moore KT, Mahaffey KW, Nessel CC, Halperin U, Califf RM, Fox KAA, Becker RC. Population pharmacokinetics and pharmacodynamics of rivaroxaban in patients with non-valvular atrial fibrillation: results from ROCKET AF. J Clin Pharmacol. 2014:54(8):917-27.

20. Xu XS, Moore K, Burton P, Stuyckens K, Mueck W, Rossenu S, Plotnikov A, Gibson M, Vermeulen A. Population pharmacokinetics and pharmacodynamics of rivaroxaban in patients with acute coronary syndromes. Brit J Clin Pharmaco. 2012;74(1):86-97.

21. Mueck W, Eriksson BI, Bauer KA, Borris L, Dahl OE, Fisher WD. Population pharmacokinetics and pharmacodynamics of rivaroxaban - an oral, direct factor Xa inhibitor - in patients undergoing major orthopaedic surgery. Clin Pharmacokinet. 2008;47(3):203-16.

22. Kubitza D, Becka M, Zuehlsdorf M, Mueck W. Body weight has limited influence on the safety, tolerability, pharmacokinetics, or pharmacodynamics of rivaroxaban (BAY 59-7939) in healthy subjects. J Clin Pharmacol. 2007; 47(2):218-26.

23. Fox KAA, Piccini JP, Wojdyla D, Becker RC, Halperin JL, Nessel CC, Paolini JF, Hankey GJ, Mahaffey KW, Patel MR, et al. Prevention of stroke and systemic embolism with rivaroxaban compared with warfarin in patients with nonvalvular atrial fibrillation and moderate renal impairment. Eur Heart J. 2011; 32(19):2387-94.

\section{Publisher's Note}

Springer Nature remains neutral with regard to jurisdictional claims in published maps and institutional affiliations.

Ready to submit your research? Choose BMC and benefit from

- fast, convenient online submission

- thorough peer review by experienced researchers in your field

- rapid publication on acceptance

- support for research data, including large and complex data types

- gold Open Access which fosters wider collaboration and increased citations

- maximum visibility for your research: over $100 \mathrm{M}$ website views per year

At BMC, research is always in progress.

Learn more biomedcentral.com/submissions 